Running title: Phenolic compounds in Lycopersicon esculentum L.

\title{
Characterization and quantification of phenolic compounds in four tomato (Lycopersicon esculentum L.) farmer' varieties in Northeastern Portugal homegardens
}

\author{
Lillian Barros ${ }^{1,2, a}$, Montserrat Dueñas ${ }^{2, a}$, José Pinela ${ }^{1}$, Ana Maria Carvalho ${ }^{1}$, \\ Celestino Santos Buelga ${ }^{2, *}$, Isabel C.F.R. Ferreira ${ }^{1, *}$
}

${ }^{1}$ CIMO/Escola Superior Agrária, Instituto Politécnico de Bragança, Campus de Santa Apolónia, Apartado 1172, 5301-855 Bragança, Portugal.

${ }^{2}$ Grupo de Investigación en Polifenoles (GIP-USAL), Facultad de Farmacia, Universidad de Salamanca, Campus Miguel de Unamuno, 37007 Salamanca, Spain.

* Authors to whom correspondence should be addressed (e-mail: csb@usal.es; telephone +34 923 294537; fax +34 923 294515; e-mail: iferreira@ipb.pt, telephone +351273303219 , fax +351273325405$)$.

${ }^{A}$ Both authors contributed equally 
Abstract Tomato (Lycopersicon esculentum L.) is one of the most widely consumed fresh and processed vegetables in the world, and contains bioactive key components. Phenolic compounds are one of those components and, according to the present study, farmer' varieties of tomato cultivated in homegardens from the northeastern Portuguese region are a source of phenolic compounds, mainly phenolic acid derivatives. Using HPLC-DAD-ESI/MS, it was concluded that a cis $p$-coumaric acid derivative was the most abundant compound in yellow ("Amarelo") and round ("Batateiro") tomato varieties, while 4-O-caffeolyquinic acid was the most abundant one in long (“Comprido") and heart (“Coração") varieties. The most abundant flavonoid was quercetin pentosylrutinoside in the four tomato varieties. Yellow tomato presented the highest levels of phenolic compounds $(54.23 \mu \mathrm{g} / \mathrm{g}$ fw), including phenolic acids (43.30 $\mu \mathrm{g} / \mathrm{g} \mathrm{fw})$ and flavonoids (10.93 $\mu \mathrm{g} / \mathrm{g} \mathrm{fw})$. The phenolic compounds profile obtained for the studied varieties is different from other tomato varieties available in different countries, which is certainly related to genetic features, cultivation conditions, and handling and storage methods associated to each sample.

Keywords Tomato; Lycopersicon esculentum; Farmers' varieties; Phenolic compounds; HPLC-DAD-ESI/MS

\section{Abbreviations}

DAD Diode Array Detector

ESI Electron Spray Ionization

HPLC High-Performance Liquid Chromatography

MS Mass Spectrometry 


\section{Introduction}

Phenolic compounds are one of the main groups of dietary phytochemicals found in fruits, vegetables and grains. They include a range of plant secondary metabolites that can be divided in different groups, i.e., flavonoids (e.g. anthocyanins, flavanols, flavones, or isoflavones), phenolic acids, tannins, stilbenes and lignans. Several of these compounds are found in nature as glycosides and/or as esters and/or methyl ethers [1].

In plants, they tend to accumulate in dermal tissues where they play a potential role in protection against UV radiation, as attractants in fruit dispersal or as defense chemicals against pathogens and predators [2]. They also exhibit a wide-range of physiological properties in animals, such as anti-allergenic, anti-atherogenic, antiinflammatory, antimicrobial, anti-thrombotic, cardioprotective, and vasodilatory effects [3]. In recent years, dietary phenolics have attracted considerable attention for their putative effects on human health, which have been associated to their antioxidant and free-radical-scavenging activities $[4,5]$.

Tomato (Lycopersicon esculentum L.) is one of the most widely consumed fresh and processed vegetables in the world and contains bioactive components such as phenolics, carotenoids and vitamins $\mathrm{C}$ and E. Carotenoids consumption has been associated with a lower risk of several types of cancer $[6,7]$ and a lower incidence of coronary heart disease [8]. Lycopene is the major carotenoid present in tomato and shows strong antioxidant activity $[9,10]$. However, lycopene alone does not account for tomato's health benefits. Phenolics have been found to act synergistically with lycopene in preventing cell damage [11].

Phenolic compounds have been extensively characterized in tomato varieties from different countries [12-16], including genetically modified tomatoes $[17,18]$. However, 
the chemical composition of tomatoes can vary among tissues of a single fruit $[19,20]$ and type of tomatoes, according to the cultivar, cultivation conditions, and handling and storage methods $[21,22]$.

There are a large number of tomato cultivars with a wide range of morphological and sensory characteristics that determine their use. In Trás-os-Montes, Northeastern Portugal, local population's lifestyles have highlighted the importance of local tomato farmers' varieties, which are grown using extensive farming techniques and considered very tasty and healthy food [23]. We had previously reported the nutritional composition and antioxidant activity of four farmers' varieties [24], but their phenolic composition was not studied. Therefore, the present work aims to characterize the phenolic profiles of these tomato farmer' varieties from Trás-os-Montes.

\section{Materials and Methods}

Samples

Four common farmer' varieties of tomato widely cultivated in rural communities from Miranda do Douro, Trás-os-Montes, Northeastern Portugal, were chosen according to morphological, sensory and usage characteristics such as size and exterior colour of mature fruits [24]: "tomate amarelo" (yellow tomato; Royal Horticultural Society Colour Chart (RHS), yellow-orange group 14), "tomate redondo or batateiro" (round tomato; RHS, Red group 42), “tomate comprido" (long tomato; RHS, Red group 34) and "tomate coração" (heart tomato; RHS, Red group 47). Tomato fruits at the ripe stage were hand harvested randomly in September 2010 from the middle of six plants of 
each of the four varieties, in selected homegardens of two villages in the studied area. The seeds were selected and kept by local farmers. The ripening stage for all samples was selected according to local consumers' criteria. The edible portion (pericarps without jointed pedicels) of six fruits of each variety was prepared and used for analysis. The samples were lyophilised (4.5 model 7750031, Labconco, Kansas, USA), reduced to a fine dried powder $(20 \mathrm{mesh})$ and kept at $-20{ }^{\circ} \mathrm{C}$ until analysis.

Standards and reagents

HPLC-grade acetonitrile was obtained from Merck KgaA (Darmstadt, Germany). Formic acid was purchased from Prolabo (VWR International, France). The phenolic compound standards were from Extrasynthese (Genay, France). All the other chemicals were of analytical grade and purchased from chemical suppliers. Water was treated in a Milli-Q water purification system (TGI Pure Water Systems, USA).

Phenolic compounds extraction procedure

Each sample $(1 \mathrm{~g})$ was extracted with $30 \mathrm{~mL}$ of methanol:water 80:20 $(v / v)$ at room temperature, with agitation $(150 \mathrm{rpm})$ for $1 \mathrm{~h}$. The extract was filtered through Whatman $\mathrm{n}^{\mathrm{o}} 4$ paper. The residue was re-extracted twice with additional $30 \mathrm{~mL}$ portions of the same solvent. The combined extracts were evaporated at $35^{\circ} \mathrm{C}$ (rotary evaporator Büchi R-210) to remove methanol. For purification, the extract solution was deposited onto a C-18 SepPak ${ }^{\circledR}$ Vac 3 cc cartridge (Phenomenex), wetted and activated with methanol followed by water; sugars and more polar substances were removed with $10 \mathrm{~mL}$ of 
water, and phenolic compounds were further eluted with $5 \mathrm{~mL}$ of methanol. The methanolic extract was concentrated under vacuum, re-dissolved in $1 \mathrm{~mL}$ of water:methanol 80:20 $(v / v)$ and filtered through a $0.22-\mu \mathrm{m}$ disposable LC filter disk for HPLC analysis.

HPLC-DAD-ESI/MS analysis

Phenolic compounds were determined by HPLC (Hewlett-Packard 1100, Agilent Technologies, Santa Clara, USA) as previously described by the authors [25]. Double online detection was carried out in the diode array detector (DAD) using $280 \mathrm{~nm}$ and $370 \mathrm{~nm}$ as preferred wavelengths and in a mass spectrometer (API 3200 Qtrap, Applied Biosystems, Darmstadt, Germany) connected to the HPLC system via the DAD cell outlet. The phenolic compounds were characterized according to their UV and mass spectra and retention times, and comparison with authentic standards when available. For quantitative analysis, a calibration curve was obtained by injection of known concentrations $(2.5-100 \mu \mathrm{g} / \mathrm{mL})$ of different standard compounds: caffeic acid $\left(\mathrm{y}=617.91 \mathrm{x}-691.51 ; R^{2}=0.9991\right) ;$ chlorogenic acid $\left(\mathrm{y}=600.27 \mathrm{x}-763.62 ; R^{2}=0.9998\right) ; p$ coumaric acid $\left(\mathrm{y}=447.12 \mathrm{x}-1580.7 ; R^{2}=0.9962\right) ;$ ferulic acid $(\mathrm{y}=779.11 \mathrm{x}-869.22$; $\left.R^{2}=0.9987\right)$; kaempferol-3-O-rutinoside (y=175.02x-43.877; $\left.R^{2}=0.9999\right)$; quercetin 3-Oglucoside $\quad\left(\mathrm{y}=316.48 \mathrm{x}-2.9142 ; \quad R^{2}=1\right) ;$ quercetin-3- $O$-rutinoside $\quad(\mathrm{y}=222.79 \mathrm{x}-243.11$; $\left.R^{2}=0.9998\right)$; and syringic acid $\left(\mathrm{y}=641.76 \mathrm{x}+246.82 ; R^{2}=0.9988\right)$. The results were expressed in $\mu \mathrm{g}$ per $\mathrm{g}$ of fresh weight (fw).

Statistical analysis 
For each sample three extracts were obtained and all the assays were carried out in triplicate. The results are expressed as mean values with standard deviation (SD). The results were analyzed using one-way analysis of variance (ANOVA) followed by Tukey's HSD Test with $\alpha=0.05$. This treatment was carried out using SPSS v. 18.0 program.

\section{Results and Discussion}

Fig. 1a shows the phenolic profile of one of the studied tomato farmer' varieties: yellow tomato (Amarelo). Phenolic acid derivatives, mainly hydroxycinnamoyl derivatives, were the most abundant compounds in all tomato varieties (Table 1).

Compounds 12 and 17 corresponded to caffeic acid and trans-p-coumaric acid respectively, identified by comparison of their UV and mass characteristics and retention time with those of commercial standards. Compounds 6 and 7 showed the same pseudomolecular ion $[\mathrm{M}-\mathrm{H}]^{-}$at $\mathrm{m} / \mathrm{z} 353$ consistent with caffeoylquinic acid isomers. Compound 7 was positively identified as 5-O-caffeoylquinic acid by comparison with an authentic standard, and also its MS fragmentation pattern [26, 27]. Compound 6 was identified as 4-O-caffeoylquinic acid based on the fragmentation pattern described by Clifford et al. [26, 27] for these compounds, with a base peak at $m / z 173$ ([quinic acid- $\left.\mathrm{H}-\mathrm{H}_{2} \mathrm{O}\right]^{-}$) accompanied by a secondary fragment ion at $\mathrm{m} / z 179$ with approximately $65 \%$ abundance of base peak. Similar reasoning was applied for the identification of compounds 11 and 13 as 4-O-p-coumaroylquinic acid and 5-O-pcoumaroylquinic acid, respectively. 
Compounds 3 and 5 presented the same pseudomolecular ion $[\mathrm{M}-\mathrm{H}]^{-}$at $\mathrm{m} / \mathrm{z} 341$ and similar fragmentation pattern with the loss of $162 \mathrm{mu}$ (hexosyl moiety) yielding a base peak at $m / z 179 \mathrm{mu}([$ caffeic acid-H]') and other two fragments at $\mathrm{m} / \mathrm{z} 161$ ([caffeic acid- $\left.\mathrm{H}-\mathrm{H}_{2} \mathrm{O}\right]^{-}$) and 135 ([caffeic acid- $\left.\mathrm{H}-\mathrm{CO}_{2}\right]^{-}$), which allowed assigning them as caffeoyl hexosides I and II, respectively. Similarly, compounds 8 and 9 with $\mathrm{MS}^{2}$ fragments at $\mathrm{m} / \mathrm{z} 145$ (base peak; [coumaric acid- $\left.\mathrm{H}_{-} \mathrm{H}_{2} \mathrm{O}\right]^{-}$) and $163(-162 \mathrm{mu}$; [coumaric acid-H]') could identified as $p$-coumaroyl hexosides. To confirm the existence of $c i$ and trans isomers, a commercial standard of (trans) p-coumaric acid was submitted to UV irradiation (366 nm, 24h). Partial transformation was observed with the appearance of a new peak at earlier retention time in the HPLC chromatogram and a different UV spectrum with $\lambda_{\max }$ at $300 \mathrm{~nm}$, which was attributed to the corresponding cis isomer (Fig. 1b). Therefore, compound 9 could be assigned as cis p-coumaroyl hexoside based on its UV spectrum with $\lambda_{\max }$ at $300 \mathrm{~nm}$. Compound 8 might be the corresponding trans isomer, although it could be expected to elute later than the cis isomer if the pattern observed for trans and cis p-coumaric acid was maintained. The fact that both compounds eluted close to each other might explain the interchange in their elution order, although we cannot discard that a different hexosyl substituent could exist in each compound, either. Thus, the compound was tentatively identified as trans $p$-coumaroyl hexoside. Furthermore, peak 10 with $\mathrm{MS}^{2}$ fragments at $m / z 193$ (-162 mu; [ferulic acid$\left.\mathrm{H}^{-}\right)$and 176 ([ferulic acid- $\left.\left.\mathrm{H}_{-} \mathrm{H}_{2} \mathrm{O}\right]^{-}\right)$was tentatively assigned as ferulic acid glucoside. The $\mathrm{MS}^{2}$ fragmentation of compound 2 presented a base peak corresponding to the ion at $m / z 163$, corresponding to $p$-coumaric acid. The observation of a loss of $162 \mathrm{mu}$ (hexosyl moiety), the base peak at $\mathrm{m} / \mathrm{z} 163$ ([coumaric acid-H]') and the presence of the ion at $m / z 325$ (coumaroyl hexose) in the $\mathrm{MS}^{2}$ fragmentation of the compound pointed 
to that it could be a derivative of a $p$-coumaroyl hexose. Furthermore, the UV spectra showing $\lambda_{\max }$ at $300 \mathrm{~nm}$, as mentioned above, suggested it as a possible cis isomer.

Compound 15 presented a pseudomolecular ion $[\mathrm{M}-\mathrm{H}]^{-}$at $m / z 359$, yielding $\mathrm{MS}^{2}$ fragments at $\mathrm{m} / \mathrm{z} 197$ (loss of a hexosyl moiety; [syringic acid-H]') and 153 (base peak; [syringic acid- $\left.\mathrm{H}-\mathrm{CO}_{2}\right]^{-}$), suggesting that it could be a syringic acid hexoside. The UV spectrum with $\lambda_{\max }$ at $274 \mathrm{~nm}$ was also coherent with a syringic acid derivative. Compound 14 presented similar UV spectrum and more $44 \mathrm{mu}\left(\mathrm{CO}_{2}\right.$, carboxyl moiety) than compound 15 . The observation of an $\mathrm{MS}^{2}$ base peak at $m / z 197$ ([syringic acid-H]') and another fragment at $\mathrm{m} / \mathrm{z} 241$ from the loss of a hexose pointed to it was a syringic acid hexoside derivative, although no final structure could be assigned.

Peaks 1 and 4 presented pseudomolecular ions identical to two non-phenolic compounds reported by Gomez-Romero et al. [13] to occur in tomato samples, i.e., benzyl alcohol dihexose and (iso)pentyl dihexose. Those authors did not present a fragmentation pattern for the first one, but the fragmentation pattern reported for (iso)pentyl dihexose was similar to the one obtained in our study. Furthermore, the early retention time and the elution order of both compounds was coherent with the proposed identities. Therefore, compounds 1 and 4 were tentatively assigned as benzyl alcohol dihexose and (iso)pentyl dihexose, respectively.

The rest of detected compounds (peaks 16, 18, 19 and 20) were identified as flavonol derivatives derived from kaempferol and quercetin. Compounds 18 and 20 were positively identified as quecetin-3-O-rutinoside and kaempferol-3-O-rutinoside, respectively, by comparison of MS fragmentation pattern and UV spectra with authentic standards. Compound 16 and 19 showed a pseudomolecular ion $[\mathrm{M}-\mathrm{H}]^{-}$at $m / z 741$ and 725, and similar $\mathrm{MS}^{2}$ fragmentation patterns releasing two fragments from the 
successive losses of pentosyl ([M-H-132]; $\mathrm{m} / \mathrm{z}$ at 609 and 593, respectively) and rutinosyl moieties ([M-H-132-308]; $\mathrm{m} / \mathrm{z}$ at 301 and 285). Thus, these compounds were tentatively identified as quercetin pentosylrutinoside and kaempferol pentosylrutinoside, respectively.

Yellow tomato (Amarelo) was the variety that presented the highest levels of phenolic compounds ( $54.23 \mu \mathrm{g} / \mathrm{g}$ fw) followed by round tomato (Batateiro, $29.42 \mu \mathrm{g} / \mathrm{g}$ ), long tomato (Comprido, $8.50 \mu \mathrm{g} / \mathrm{g}$ ) and heart tomato (Coração, $3.72 \mu \mathrm{g} / \mathrm{g}$ ) (Table 1). Phenolic acids were the most abundant group, being compound 2 (cis p-coumaric acid derivative) predominating in Amarelo and Batateiro tomato varieties, and 4-Ocaffeolyquinic acid the most abundant compound in Comprido and Coração varieties. The non-phenolic compound, benzyl alcohol dihexose, was also predominant in all tomato varieties. The most abundant flavonoid was quercetin pentosylrutinoside in all the studied tomato varieties.

According to literature, chlorogenic acid (i.e., 5-O-caffeoylquinic acid) was the main phenolic compound in tomato and the most extensively studied $[14-16,18]$, whereas flavonoids are represented by flavanones (naringenin glycosylated derivatives) and flavonols (quercetin, rutin and kaempferol glycosylated derivatives) [12, 13, 15, 17]. In the samples studied herein, main phenolics also corresponded to hydroxycinnamoyl derivatives, although 5-O-caffeoylquinic acid was not the majority compound; furthermore, neither naringenin nor naringenin glycosylated derivatives were found; which can be interpreted as composition characteristics of the studied tomato samples, as related to genetic features, cultivation conditions, and/or handling and storage methods associated to each sample $[21,22]$. In fact, phenolic compounds have been reported as 
cultivar- and variety-distinguishing factors in some plant products [28], being dependent on genotype and environmental factors [29].

Acknowledgements L. Barros thanks to FCT, POPH-QREN and FSE for her grant (SFRH/BPD/4609/2008). M. Dueñas thanks to the Programa Ramón y Cajal for a contract. The GIPUSAL is financially supported by the Spanish Ministerio de Ciencia e Innovación through the Consolider-Ingenio 2010 Programme (FUN-C-FOOD, CSD2007-00063), and Junta de Castilla y León (Grupo de Investigación de Excelencia, GR133).

\section{References}

1. Garcia-Salas P, Morales-Soto A, Segura-Carretero A, Fernández-Gutiérrez A (2010) Phenolic-compound-extraction systems for fruit and vegetable samples. Molecules $15: 8813-8826$

2. Tsao R, McCallum J (2009) Chemistry of Flavonoids. In Laura A. de la Rosa, Emilio Alvarez-Parrilla, \& Gustavo Gonzalez-Aguilar (Eds.), Fruit and vegetable phytochemicals: Chemistry, nutritional value and stability (pp. 131-153). Ames, Iowa: Blackwell Publishing (chapter 5)

Balasundram N, Sundram K, Samman S (2006) Phenolic compounds in plants and agriindustrial by-products: Antioxidant activity, occurrence, and potential uses. Food Chem 99:191-203

4. Fernández-Panchon MS, Villano D, Troncoso AM, Garcia-Parrilla MC (2008) Antioxidant activity of phenolic compounds: from in vitro results to in vivo evidence. Crit Rev Food Sci Nutr 48:649-671

5. Heim KE, Tagliaferro AR, Bobilya DJ (2002) Flavonoid antioxidants: chemistry, metabolism and structure-activity relationships. J Nutr Biochem 13:572-584 
6. Grieb SMD, Theis RP, Burr D, Benardot D, Siddiqui T, Asal NR (2009) Food groups and renal cell carcinoma: results from a case-control study. J Am Diet Assoc 109:656-667

7. Zhang CX, Ho SC, Chen YM, Fu JH, Cheng SZ, Lin FY (2009). Greater vegetable and fruit intake is associated with a lower risk of breast cancer among Chinese women. Int J Cancer 125:181-188

8. Stahl W, Sies H (2005) Bioactivity and protective effects of natural carotenoids. Biochim Biophys Acta-Mol Bas Dis 1740:101-107

9. Agarwal S, Rao AV (2000) Tomato lycopene and its role in human health and chronic diseases. CMAJ 163:739-744

10. Clinton SK (1998) Lycopene: Chemistry, biology, and implications for human health and disease. Nutr Rev 56:35-51

11. Shen YC, Chen SL, Wang CK (2007) Contribution of tomato phenolics to antioxidation and down-regulation of blood lipids. J Agric Food Chem 55:6475-6481

12. Bahorun T, Luximon-Ramma A, Crozier A, Aruoma OI (2004) Total phenol, flavonoid, proanthocyanidin and vitamin $\mathrm{C}$ levels and antioxidant activities of Mauritian vegetables. J Sci Food Agric 84:1553-1561

13. Gómez-Romero M, Segura-Carretero A, Fernández-Gutiérrez A (2010) Metabolite profiling and quantification of phenolic compounds in methanol extracts of tomato fruit. Phytochemistry 71:1848-1864

14. Martinez-Valverde I, Periago MJ, Provan G, Chesson A (2002) Phenolic compounds, lycopene and antioxidant activity in commercial varieties of tomato (Lycopersicon esculentum). J Sci Food Agric 82:323-330 
15. Slimestad R, Fossen T, Verheul MJ (2008). The flavonoids of tomatoes. J Agric Food Chem 56:2436-2441

16. Vallverdú-Queralt A, Jáuregui O, Medina-Remón A, Andrés-Lacueva C, LamuelaRaventós RM (2010) Improved characterization of tomato polyphenols using liquid chromatography/electrospray ionization linear ion trap quadrupole orbitrap mass spectrometry and liquid chromatography/electrospray ionization tandem mass spectrometry. Rapid Comun Mass Spectr 24:1-7

17. Le Gall G, Dupont MS, Mellon FA, Davis AL, Collins GJ, Verhoeyen ME et al (2003) Characterization and content of flavonoid glycosides in genetically modified tomato (Lycopersicon esculentum) fruits. J Agric Food Chem 51:2438-2446

18. Niggeweg R, Michael AJ, Martin C (2004) Engineering plants with increased levels of the antioxidant chlorogenic acid. Nature Biotech 22:746-754

19. Moco S, Capanoglu E, Tikunov Y, Bino RJ, Boyacioglu D, Hall RD, Vervoort J, de Vos CHR 2007. Tissue specialisation at the metabolite level is perceived during the development of tomato fruit. J Exp Bot 58:4131-4136

20. Peng Y, Zhang Y, Ye J (2008) Determination of phenolic compounds and ascorbic acid in different fractions of tomato by capillary electrophoresis with electrochemical detection. J Agric Food Chem 56:1838-1844

21. Davies JN, Hobson GE (1981) The constituent of tomato fruit - the influence of environment, nutrition and genotype. Crit Rev Food Sci Nutr 15:205-280

22. Dumas Y, Dadomo M, DiLucca G, Grolier P (2003) Effects of environmental factors and agricultural techniques on antioxidant content of tomatoes. J Sci Food Agric 83:369-382 
23. Carvalho AM, Morales R (2010) Persistence of wild food and wild medicinal plant knowledge in a North-Eastern region of Portugal. In: Pardo de Santayana, M., Pieroni, A., Puri, R. (Eds.), Ethnobotany in the New Europe: People, Health, Wild Plant Resources. Berghahn Books, Oxford, pp. 147-171

24. Pinela J, Barros L, Carvalho AM, Ferreira ICFR (2012) Nutritional composition and antioxidant activity of four tomato (Lycopersicon esculentum L.) farmer' varieties in Northeastern Portugal homegardens. Food Chem Toxicol 50:829-834

25. Barros L, Dueñas M, Carvalho AM, Ferreira ICFR, Santos-Buelga C (2012) Characterization of phenolic compounds in flowers of wild medicinal plants from Northeastern Portugal. Food Chem Toxicol 50:1576-1582

26. Clifford MN, Johnston KL, Knight S, Kuhnert NA (2003) A hierarchical scheme for LC-MS ${ }^{\mathrm{n}}$ identification of chlorogenic acids. J Agric Food Chem 51:2900-2911

27. Clifford MN, Knight S, Kuhnert NA (2005) Discriminating between the six isomers of dicaffeoylquinic acid by LC-MS ${ }^{\mathrm{n}}$. J Agric Food Chem 53:3821-3832

28. Klepacka J, Gujska E, Michalak J (2011) Phenolic compounds as cultivar- and variety-distinguishing factors in some plant products. Plant Food Hum Nutr 66:64-69

29. Beato VM, Orgaz F, Mansilla F, Montaño A (2011) Changes in phenolic compounds in garlic (Allium sativum L.) owing to the cultivar and location of growth. Plant Food Hum Nutr 66: 218-223 


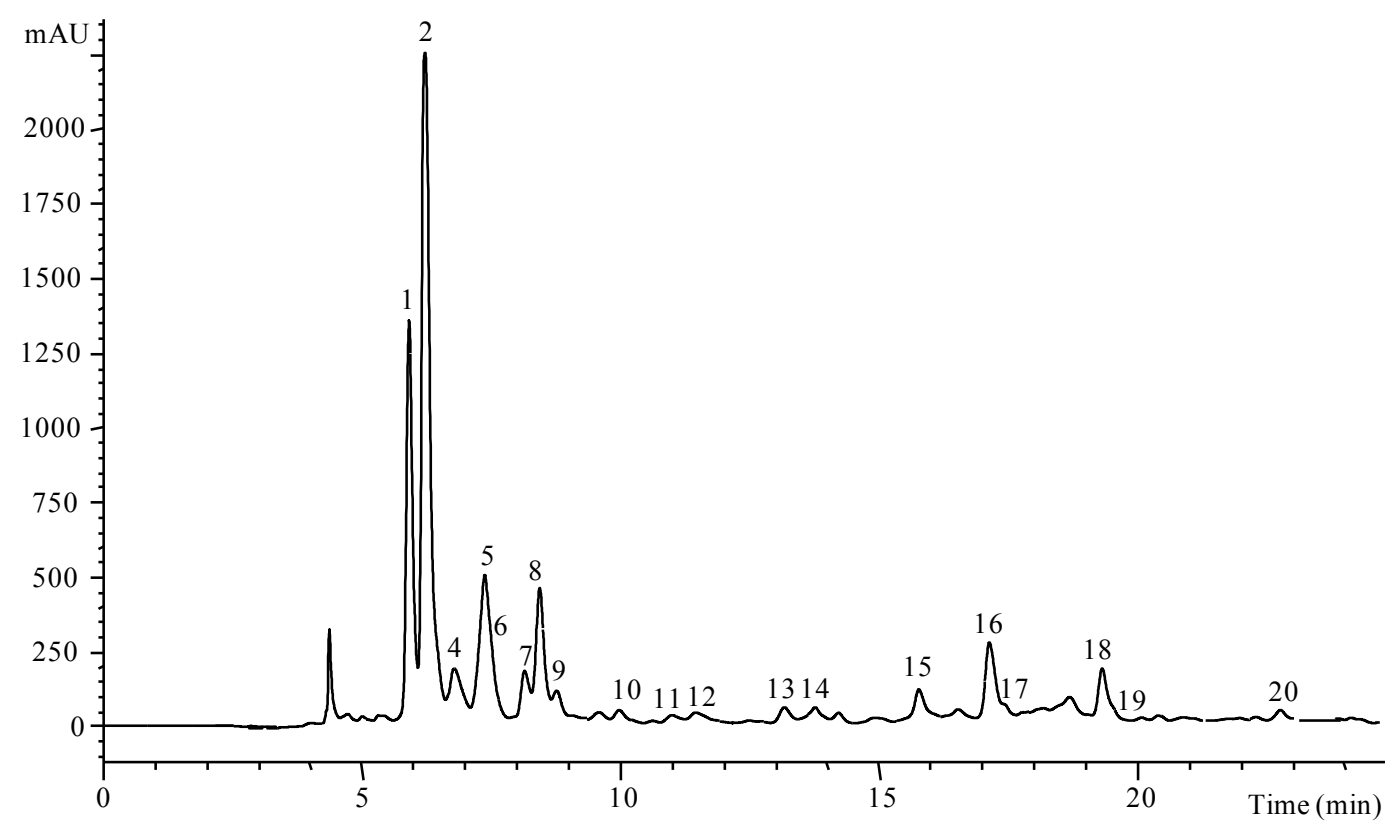

(a)

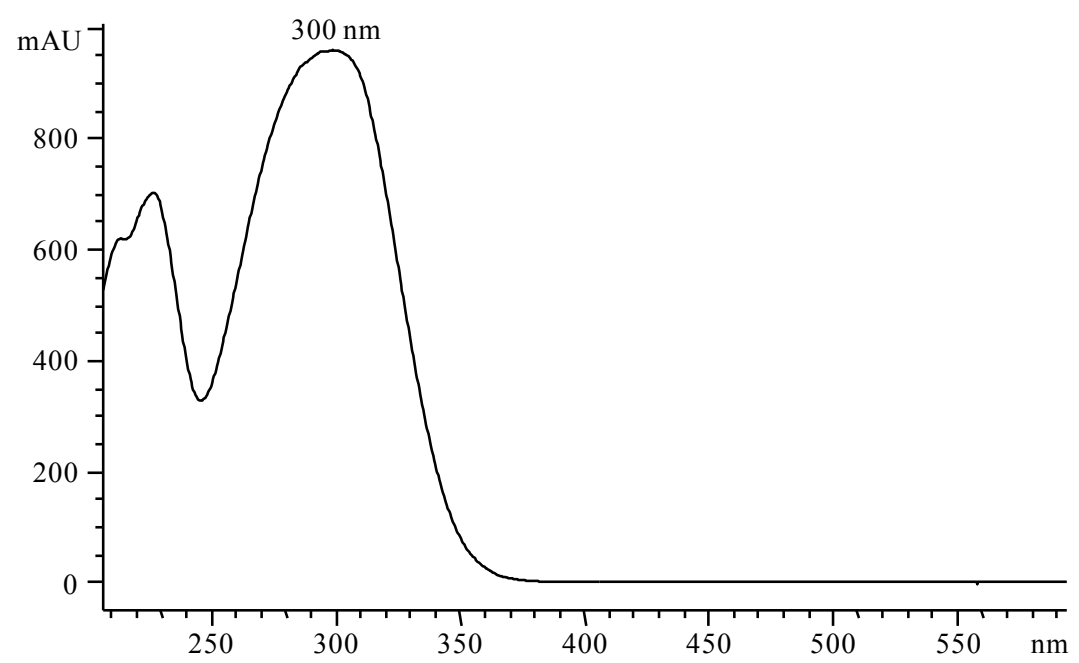

(b)

Fig. 1. Individual chromatogram of yellow tomato variety (Amarelo) recorded at 280 nm (a) and UV spectrum of compounds 2 and 9 (b). 
Table 1 Retention time (Rt), wavelengths of maximum absorption in the visible region $\left(\lambda_{\max }\right)$, mass spectral data, tentative identification and concentration of phenolic acids and flavonoids in four different tomato Portuguese farmer' varieties.

Compounds identification

\begin{tabular}{|c|c|c|c|c|c|c|c|c|c|}
\hline \multicolumn{6}{|c|}{ Compounds identification } & \multicolumn{4}{|c|}{ Concentration of the identified compounds ( $\mu \mathrm{g} / \mathrm{g}$ fw) } \\
\hline Compound & Rt (min) & $\lambda_{\max }(\mathrm{nm})$ & $\begin{array}{l}\text { Molecular ion } \\
{[\mathrm{M}-\mathrm{H}]^{-}(\mathrm{m} / \mathrm{z})}\end{array}$ & $\operatorname{MS}^{2}(m / z)$ & Tentative identification & Amarelo & Batateiro & Comprido & Coração \\
\hline 1 & 5.93 & $286 / 320$ sh & 431 & $341(2), 269(38), 179(4), 161(52), 113(15)$ & Benzyl alcohol dihexose** & $12.03 \pm 0.84^{\mathrm{a}}$ & $7.46 \pm 0.28^{b}$ & $2.37 \pm 0.07^{\mathrm{c}}$ & $0.84 \pm 0.03^{\mathrm{d}}$ \\
\hline 2 & 6.24 & 300 & 651 & $489(5), 325(4), 205(2), 163(100), 119(72)$ & cis $p$-Coumaric acid derivative & $17.96 \pm 1.21^{\mathrm{a}}$ & $7.34 \pm 2.19^{\mathrm{b}}$ & $0.68 \pm 0.02^{\mathrm{c}}$ & $0.40 \pm 0.01^{\mathrm{c}}$ \\
\hline 3 & 6.48 & 328 & 341 & $179(100), 161(58), 135(57)$ & Caffeic acid hexoside I & nd & nd & $1.29 \pm 0.01^{\mathrm{a}}$ & $0.76 \pm 0.10^{\mathrm{b}}$ \\
\hline 4 & 6.80 & 258 & 411 & $249(24), 161(24), 113(7)$ & (Iso)pentyl dihexose & $1.97 \pm 0.06^{\mathrm{a}}$ & $1.48 \pm 0.27^{\mathrm{b}}$ & $0.22 \pm 0.00^{\mathrm{c}}$ & $0.01 \pm 0.00^{\mathrm{c}}$ \\
\hline 5 & 7.39 & 320 & 341 & $179(100), 161(13), 135(62)$ & Caffeic acid hexoside II & $6.57 \pm 0.15^{\mathrm{a}}$ & $5.21 \pm 1.63^{\mathrm{a}}$ & $0.53 \pm 0.03^{\mathrm{b}}$ & $0.25 \pm 0.03^{\mathrm{b}}$ \\
\hline 6 & 7.52 & 314 & 353 & 191(47)179(65), 173(100), 161(6), 135(45) & 4-O-Caffeolyquinic acid** & $4.38 \pm 0.21^{\mathrm{a}}$ & $3.29 \pm 0.91^{\mathrm{a}}$ & $3.81 \pm 0.77^{\mathrm{a}}$ & $0.81 \pm 0.19^{\mathrm{b}}$ \\
\hline 7 & 8.16 & 326 & 353 & 191(100), 179(11), 173(7), 161(15), 135(6) & 5-O-Caffeolyquinic acid & $3.83 \pm 0.34^{\mathrm{a}}$ & $1.92 \pm 0.22^{\mathrm{b}}$ & $0.20 \pm 0.03^{\mathrm{c}}$ & $0.03 \pm 0.00^{\mathrm{c}}$ \\
\hline 8 & 8.44 & 316 & 325 & $163(40), 145(100), 119(26)$ & trans $p$-Coumaric acid hexoside & $3.90 \pm 0.08^{\mathrm{a}}$ & $1.60 \pm 0.51^{\mathrm{b}}$ & $0.02 \pm 0.00^{\mathrm{c}}$ & $0.02 \pm 0.00^{\mathrm{c}}$ \\
\hline 9 & 8.77 & 300 & 325 & $163(29), 145(100), 119(17)$ & cis $p$-Coumaric acid hexoside & $0.61 \pm 0.05^{\mathrm{a}}$ & $0.44 \pm 0.14^{\mathrm{b}}$ & $0.16 \pm 0.01^{\mathrm{c}}$ & $0.04 \pm 0.00^{\mathrm{c}}$ \\
\hline 10 & 9.97 & 330 & 355 & $193(30), 175(100), 161(43), 135^{*}$ & Ferulic acid hexoside & $0.97 \pm 0.07^{\mathrm{a}}$ & $0.27 \pm 0.06^{\mathrm{b}}$ & $0.04 \pm 0.00^{\mathrm{c}}$ & $0.03 \pm 0.00^{\mathrm{c}}$ \\
\hline 11 & 11.00 & 312 & 337 & $191^{*}, 173(100), 163(20), 155(8), 137(8)$ & 4-O-p-Coumarolyquinic acid & $0.04 \pm 0.00^{\mathrm{a}}$ & $0.01 \pm 0.00^{\mathrm{b}}$ & $0.01 \pm 0.00^{\mathrm{b}}$ & $\operatorname{tr}$ \\
\hline 12 & 11.45 & 328 & 179 & $135(100)$ & Caffeic acid & $0.46 \pm 0.07^{\mathrm{a}}$ & $0.20 \pm 0.06^{\mathrm{b}}$ & $0.03 \pm 0.00^{\mathrm{c}}$ & $0.02 \pm 0.00^{\mathrm{c}}$ \\
\hline 13 & 13.16 & 312 & 337 & $191(100), 173(12), 163(16), 155^{*}$ & 5-O-p-Coumarolyquinic acid & $0.41 \pm 0.08^{\mathrm{a}}$ & $0.33 \pm 0.00^{\mathrm{b}}$ & $0.02 \pm 0.00^{\mathrm{c}}$ & $0.01 \pm 0.00^{\mathrm{c}}$ \\
\hline 14 & 13.75 & 274 & 403 & $241(80), 197(100), 179(10), 137(10)$ & Syringic acid hexoside derivative & $0.35 \pm 0.00^{\mathrm{a}}$ & $0.83 \pm 0.00^{\mathrm{b}}$ & $0.17 \pm 0.01^{\mathrm{c}}$ & $0.11 \pm 0.03^{\mathrm{d}}$ \\
\hline 15 & 15.75 & 274 & 359 & $197(34), 153(100), 135(8)$ & Syringic acid hexoside & $1.11 \pm 0.01^{\mathrm{a}}$ & $1.21 \pm 0.01^{\mathrm{b}}$ & $0.62 \pm 0.08^{\mathrm{c}}$ & $0.39 \pm 0.03^{\mathrm{d}}$ \\
\hline 16 & 17.08 & 352 & 741 & $609 *, 301(28)$ & Quercetin pentosylrutinoside & $4.76 \pm 0.11^{\mathrm{a}}$ & $2.81 \pm 0.05^{\mathrm{b}}$ & $0.34 \pm 0.07^{\mathrm{c}}$ & $0.60 \pm 0.02^{\mathrm{d}}$ \\
\hline 17 & 17.26 & 312 & 163 & $119(100)$ & trans- $p$-Coumaric acid & $2.70 \pm 0.10^{\mathrm{a}}$ & $0.67 \pm 0.04^{\mathrm{b}}$ & $0.13 \pm 0.01^{\mathrm{c}}$ & $0.09 \pm 0.00^{\mathrm{c}}$ \\
\hline 18 & 19.32 & 330 & 609 & $301(100)$ & Quercetin-3-O-rutinoside & $4.68 \pm 0.49^{\mathrm{a}}$ & $2.62 \pm 0.80^{\mathrm{b}}$ & $0.39 \pm 0.06^{\mathrm{c}}$ & $0.09 \pm 0.00^{\mathrm{c}}$ \\
\hline 19 & 19.50 & 334 & 725 & $593 *, 285(23)$ & Kaempferol pentosylrutinoside & $1.25 \pm 0.11^{\mathrm{a}}$ & $0.57 \pm 0.14^{\mathrm{b}}$ & $0.03 \pm 0.01^{\mathrm{c}}$ & $0.04 \pm 0.00^{\mathrm{c}}$ \\
\hline \multirow[t]{5}{*}{20} & 22.79 & 318 & 593 & $285(100)$ & Kaempferol-3- $O$-rutinoside & $0.24 \pm 0.02^{\mathrm{a}}$ & $0.10 \pm 0.03^{\mathrm{b}}$ & $0.05 \pm 0.00^{\mathrm{c}}$ & $0.03 \pm 0.00^{\mathrm{c}}$ \\
\hline & & & & & Total phenolic acids & $43.30 \pm 2.03^{\mathrm{a}}$ & $23.32 \pm 1.25^{\mathrm{b}}$ & $7.69 \pm 0.70^{\mathrm{c}}$ & $2.96 \pm 0.27^{\mathrm{d}}$ \\
\hline & & & & & Total flavonoids & $10.93 \pm 0.52^{\mathrm{a}}$ & $6.10 \pm 1.01^{\mathrm{b}}$ & $0.81 \pm 0.13^{\mathrm{c}}$ & $0.76 \pm 0.02^{\mathrm{c}}$ \\
\hline & & & & & Total phenolic compounds & $54.23 \pm 2.55^{\mathrm{a}}$ & $29.42 \pm 2.26^{\mathrm{b}}$ & $8.50 \pm 0.58^{\mathrm{c}}$ & $3.72 \pm 0.25^{\mathrm{d}}$ \\
\hline & & & & & Total non-phenolic compounds & $14.00 \pm 0.90^{\mathrm{a}}$ & $8.94 \pm 0.55^{\mathrm{b}}$ & $2.59 \pm 0.07^{\mathrm{c}}$ & $0.85 \pm 0.04^{\mathrm{d}}$ \\
\hline
\end{tabular}

Figures in brackets after $\mathrm{MS}^{2}$ fragment ions refer to their relative abundances. *Relative abundance $<2 \%$. nd- not detected; tr-traces. ${ }^{*}$ Concentrations of compound 1 and 4 were expressed as equivalents of caffeic acid and syringic acid, respectively. In each row different letters mean significant differences ( $<<0.05)$. 